Aplicação do Código Florestal Brasileiro como Subsídio para o Planejamento Ambiental: um Estudo de Caso na Região Noroeste do Estado do Rio de Janeiro

Eberval Marchioro, Nelson Ferreira Fernandes, José Ronaldo de Macedo,Silvio B. Bhering, Alexandre Ortega

\title{
APLICAÇÃO DO CÓDIGO FLORESTAL BRASILEIRO COMO SUBSÍDIO PARA O PLANEJAMENTO AMBIENTAL: UM ESTUDO DE CASO NA REGIÃO NOROESTE DO ESTADO DO RIO DE JANEIRO
}

\author{
Applying the Brazilian Forest Code as support to environmental planning: a case study in \\ northwestern Rio de Janeiro State
}

Eberval Marchioro

Universidade Federal Fluminense - Curso de Geografia Pólo Universitário de Campos dos Goytacazes (UFF/PUCG) ebervalm@gmail.com Campos dos Goytacazes/RJ - Brasil

Nelson Ferreira Fernandes Programa de Pós-graduação em Geografia/UFRJ nelsonff@uol.com.br Rio de Janeiro/RJ - Brasil

José Ronaldo de Macedo Eng. Agrônomo da Embrapa Solos Pesquisador da Embrapa/RJ jrmacedo@cnps.embrapa.br Rio de Janeiro/RJ - Brasil

Silvio B. Bhering

Eng. Agrônomo da Embrapa Solos Pesquisador da Embrapa/RJ silviobhering@gmail.com Rio de Janeiro/RJ - Brasil

Alexandre Ortega Gonçalves Eng. Agrônomo da Embrapa Solos aortega@cnps.embrapa.br Rio de Janeiro/RJ - Brasil

Artigo recebido para publicação em 12/09/2009 e aceito para publicação em 01/04/2010

RESUMO: O trabalho verificou a aplicação do Código Florestal Brasileiro (CFB) na bacia do Córrego Santa Maria, na região Noroeste Fluminense (RJ), como subsídio para o planejamento ambiental. Essa bacia localiza-se inteiramente no Município de São José de Ubá e vem sendo submetida a diferentes processos de uso e ocupação do solo, culminando com problemas erosivos e hídricos. Para realização do trabalho foi elaborado o mapa de uso e ocupação do solo atual por meio de classificação automática supervisionada, utilizando-se fotos aéreas da Companhia de Energia do Rio de Janeiro (CERJ) e do 
Aplicação do Código Florestal Brasileiro como Subsídio para o Planejamento Ambiental:

um Estudo de Caso na Região Noroeste do Estado do Rio de Janeiro

Eberval Marchioro, Nelson Ferreira Fernandes, José Ronaldo de Macedo,Silvio B. Bhering, Alexandre Ortega

Departamento de Recursos Minerais - DRM/RJ. Para elaboração do mapa de uso e ocupação do solo com o cenário estabelecido no artigo $2^{\circ}$ do CFB foi criada uma faixa de entorno. Os resultados indicam que ocorreria conflito entre a utilização do CFB e o uso atual para ás áreas a agricultura e pecuária, solo exposto e área urbana. No caso da agricultura e pecuária, o uso conflitante poderia ser amenizado com práticas de manejo e conservação adequadas. A aplicação do CFB contribuiria significativamente para aumento das APP (floresta), promovendo aumento da infiltração de água no solo e recarga do sistema aquifero, diminuição do escoamento superficial e da erosão dos solos.

Palavras chave: Bacia hidrográfica. Código Florestal Brasileiro. Erosão dos solos.

\begin{abstract}
This studied verified the application of the Brazilian Forest Code (CFB) in the Santa Maria creek basin, in northwestern Rio de Janeiro, as a support to environmental planning. This basin is fully located in the county of São José de Ubá, and it has been subject to different processes of soil use and occupation, resulting in water and erosion problems. In order to perform the study, a map of current soil use and occupation was designed through automatic supervised classification, using air photos of Companhia de Energia do Rio de Janeiro -CERJ (Rio de Janeiro Power Company) and Mineral Resources Department -DRM/RJ. In order to design the map of soil use and occupation in compliance with the scenario established in article 2 of the CFB, a surrounding belt (buffer zone) was created. The results show that there would be conflicts between the CFB application and the current use of areas for agriculture, animal husbandry, exposed soil and urban area. In agriculture and animal husbandry, the conflicting use could be softened with adequate handling and conservation practices. Applying the CFB would significantly contribute to increasing APP (forest), promoting increased water seepage in soil and water system recharge, and decreasing overland runoff and soil erosion.
\end{abstract}

Keywords: Hydrographic Basin. Brazilian Forest Code. Soil Erosion.

\section{INTRODUÇÃO}

A degradação ambiental é um problema que vêm se agravando ao longo do tempo, promovendo um reordenamento do sistema de produção e da apropriação do espaço pelas forças produtivas (CUNHA e GUERRA, 1996).

A apropriação de novas áreas pelas forças produtivas para, por exemplo, a agricultura, em bacias hidrográficas é realizada na maioria das vezes, sem práticas de manejo e conservação gerando uma situação de conflito entre a sociedade e a natureza, pautada fundamentalmente nos princípios econômicos vigentes (CASSETI, 1991).

No Brasil, desde a chegada dos primeiros colonizadores, iniciou-se o processo de degradação ambiental devido à retirada da cobertura vegetal primitiva para exportação de madeiras e, posteriormente, para a implantação de sistemas agropecuários, expondo o solo à erosão hídrica (MARCHIORO, 2008).

Na região sudeste do Brasil, por exemplo, o Estado do Rio de Janeiro perdeu cerca de $30 \mathrm{mil}$ hectares de sua Mata Atlântica entre o período de 1985 e 1990, que foram substituídos por moradias e atividade agropecuária, com destaque para a região da Serra do Mar, para o Nordeste e o Noroeste do Rio de Janeiro (CIDE, 2003). Nesta última região, tal situação ocorre há décadas, devido, inicialmente, a implantação do café, pecuária extensiva e, por fim, a atividade olerícola de tomate em substituição a Mata Atlântica original, contribuindo para o aumento nas taxas de produção de sedimentos pela erosão dos solos, aparecimento de feições erosivas,

Sociedade \& Natureza, Uberlândia, 22 (1): 11-21, abr. 2010 
desaparecimento de rios, migração de nascentes, aumento da quantidade de poluentes que atingem os cursos fluviais e diminuição da recarga dos sistemas de aquíferos (MOURA, 2005).

$\mathrm{Na}$ tentativa de ordenar os diversos interesses envolvidos na utilização das terras, o Estado brasileiro vem regulamentando o uso e ocupação do solo por meio da promulgação de leis, decretos e resoluções, desde a década de 1930. Mas foi a partir da promulgação da Lei $\mathrm{n}^{\circ} .4 .771$ de 15 de setembro de 1965, que instituiu o Código Florestal Brasileiro, parcialmente alterada pela Lei $\mathrm{n}^{\circ} .7 .803$ de 18 de julho de 1989, que o Estado participa ativamente da regulamentação do uso e ocupação do solo. Com essa Lei, o Estado buscou ordenar o uso e ocupação do solo brasileiro, visando contribuir para minimização da degradação ambiental, bem como, a situação de conflito entre o sistema produtivo e a preservação ambiental, verificada em amplas áreas do País (MARCHIORO, 2008).

Diante do contexto apresentado no Brasil e, também, no noroeste do Estado do Rio do Janeiro, associado à ausência de orientação técnica aos produtores rurais e às escassas práticas de manejo e conservação do solo, esse trabalho visa aplicar o artigo $2^{\circ}$ do Código Florestal Brasileiro (CFB) na bacia hidrográfica do Córrego Santa Maria, identificando possíveis conflitos ambientais entre o sistema produtivo e as Áreas de Proteção Ambiental (APP), subsidiando o planejamento ambiental.

\section{2. ÁREA DE ESTUDO}

A bacia do Córrego Santa Maria localizase totalmente no Município de São José de Ubá, na região noroeste do Rio de Janeiro que é denominada de noroeste fluminense, apresentando uma área de 13,56 $\mathrm{Km}^{2}$ ou 1.356 ha, como pode ser visto na FIGURA 1.

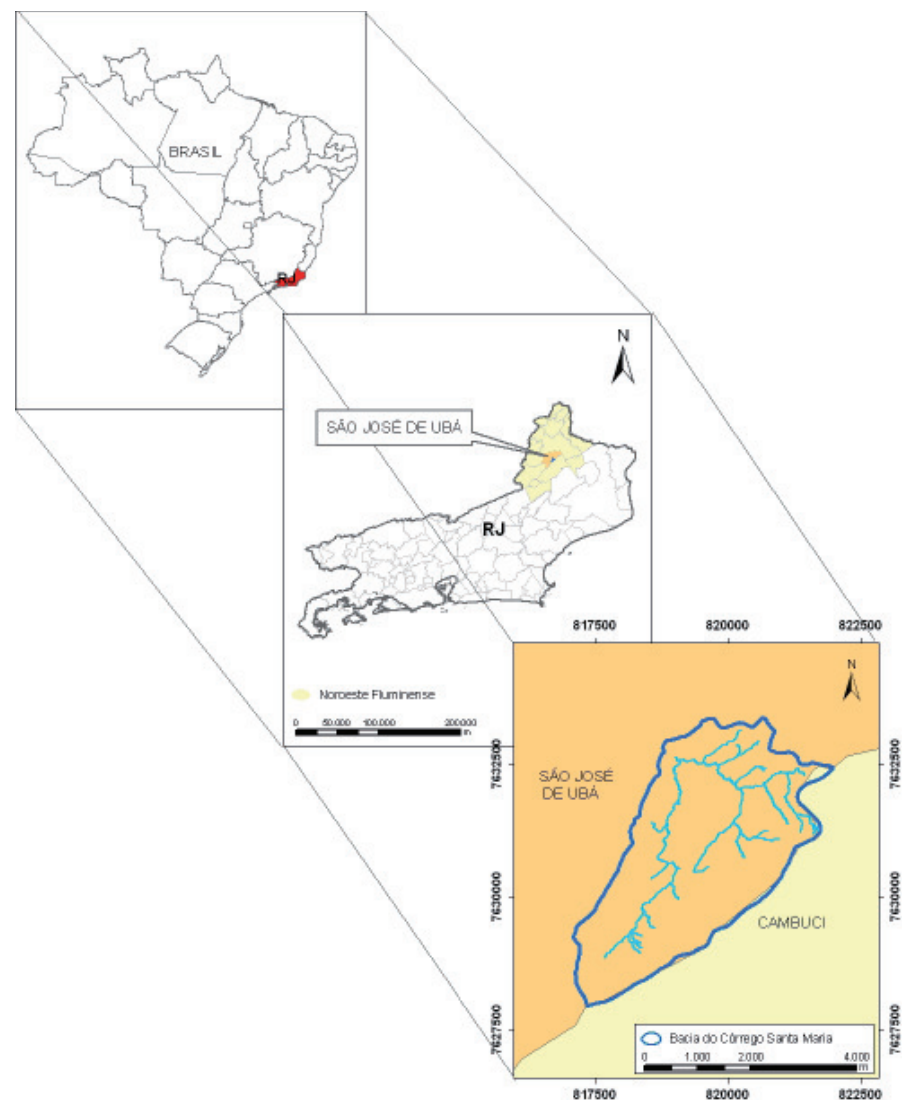

FIGURA 1: Localização geográfica da bacia hidrográfica do Córrego Santa Maria no Município de São José de Ubá no noroeste do Estado do Rio de Janeiro. 
Aplicação do Código Florestal Brasileiro como Subsídio para o Planejamento Ambiental:

um Estudo de Caso na Região Noroeste do Estado do Rio de Janeiro

Eberval Marchioro, Nelson Ferreira Fernandes, José Ronaldo de Macedo,Silvio B. Bhering, Alexandre Ortega

A bacia hidrográfica do Córrego Santa Maria é uma sub-bacia do rio São Domingos, que por sua vez, é sub-bacia do rio Muriaé, que drena suas águas para a bacia do rio Paraíba do Sul, um dos mais importantes sistemas hidrográficos do Brasil (Prado et al., 2005).

Desde 1940 a população total do Município de São José de Ubá está diminuindo, devido a migração para os outros centros urbanos, ocasionado pela falta de oportunidades de trabalho, resultando em um total populacional atual de 6.829 habitantes. A base econômica do município é a exploração agropecuária. A pecuária é do tipo misto, sendo tanto a leiteira como a de corte de baixa produtividade. Do ponto de vista agrícola, destaque para a olerícula de tomate e pimentão, que em sua maioria é praticada sem manejo adequado, com quantidades significativas de fungicidas e inseticidas, entre outros, poluindo os recursos hídricos (PRADO et al., 2005). Atualmente a produção de tomate é a segunda maior do Estado do Rio de Janeiro, sendo a principal fonte de emprego e renda para a maioria da população residente, sendo denominado por alguns, como o "ouro vermelho" (MOURA, 2005).

O clima de São José de Ubá foi caracterizado por Gonçalves et al. (2006) como do tipo Aw, ou seja, tropical quente e úmido com estações climáticas bem definidas. Baseado em dados de 2005 a 2007 coletados na bacia, verifica-se que a precipitação média anual foi de $1.283,72 \mathrm{~mm}$. O trimestre consecutivo mais chuvoso é de novembro a janeiro, totalizando $663,29 \mathrm{~mm}$, o equivalente a $51,66 \%$ do total pluviométrico. O mês mais chuvoso é janeiro, com $314,38 \mathrm{~mm}$, representando $24,48 \%$ do total pluviométrico. $\mathrm{O}$ trimestre consecutivo seco ocorre entre o período de junho, julho e agosto, com índices pluviométricos de $28,17 \mathrm{~mm} ; 28,34 \mathrm{~mm}$ e $7,28 \mathrm{~mm}$, representando em termos percentuais o equivalente a 4,97\% do índice pluviométrico médio do período citado A temperatura média para o período de 1960 - 1990 é de $23,1^{\circ} \mathrm{C}$, sendo o mês de fevereiro, com $26,4^{\circ} \mathrm{C}$, o mais quente e o de junho, o mais frio, com $19,9^{\circ} \mathrm{C}$. O trimestre mais quente é o compreendido entre janeiro e março, e o mais frio entre junho a agosto (MARCHIORO, 2008).

As unidades geológicas encontradas na bacia hidrográfica do Córrego Santa Maria são as de São José de Ubá e Vista Alegre (Complexo Juiz de Fora), Catalunha (Complexo Paraíba do Sul) e os Sedimentos Quaternários (REIS e MANSUR, 1995). A bacia possui importante descontinuidade geológica longitudinal, com rumo NE-SW, e as rochas encontram-se cortadas por conjunto de fraturas, predominando os trends NNW-SSE e NESW (concordante com a estruturação geológica da bacia) concentradas na parte norte da bacia (Domínio Juiz de Fora), devido à heterogeneidade das rochas e uma estruturação milonítica mais pronunciada (HEILBRON, et al., 2005).

Quanto a geomorfologia, a bacia está inserida na unidade Depressão Interplanáltica com Alinhamentos Serranos do Norte-Noroeste Fluminense (DANTAS, 2000). Essa unidade caracteriza-se por apresentar contraste brusco entre feições homogêneas de colinas, morros e morrotes associados aos alinhamentos serranos elevados.

As classes de solos predominantes na bacia são os Cambissolos Háplicos lépticos que abrangem $44 \%$ da área, os Argilossolos Vermelho-Amarelos abrangendo uma área de $18,5 \%$ e os Neossolos Litólicos abrangendo uma área $16,7 \%$, que em conjunto totalizam 79,2 da área da bacia. Os restantes $20,8 \%$ são compostos, em ordem decrescente de área, pelos Cambissolos Háplicos gleicos, Gleissolos Háplicos e Afloramento de rocha (BHERING et al., 2005; ZARONI, 2006).

\section{MATERIAIS E MÉTODOS}

Para elaboração desse trabalho inicialmente foi feito o mapa de uso e ocupação atual e, posteriormente, o mapa levando-se em consideração o item do Código Florestal destacado anteriormente.

A elaboração preliminar do mapa de uso e ocupação do solo atual foi realizada por Zaroni 
Aplicação do Código Florestal Brasileiro como Subsídio para o Planejamento Ambiental: um Estudo de Caso na Região Noroeste do Estado do Rio de Janeiro Eberval Marchioro, Nelson Ferreira Fernandes, José Ronaldo de Macedo,Silvio B. Bhering, Alexandre Ortega

(2006), modificado por Marchioro (2008), utilizandose o Sistema de Informação Geográfica (ArcGis).

Para confecção do mapa de uso e ocupação preliminar do solo atual por Zaroni (2006), utilizouse fotografias aéreas do tipo pancromáticas, na escala de 1:20.000 e 1:30.000 de 2000, fornecidos pela Companhia de Eletricidade do Rio de Janeiro (CERJ). Nesse mapeamento, a autora citada verificou uma faixa da bacia do Córrego Santa Maria que não foi recoberta pelo sobrevôo, culminando na ausência do mapeamento dessa porção.

Para solucionar o problema no mapeamento supracitado, realizou-se foto-interpretação e preenchimento manual dessa área não recoberta pelo sobrevôo da CERJ. Para tal, foram utilizadas fotografias aéreas disponibilizadas pelo Departamento de Recursos Minerais - DRM/RJ do Vôo da Força Área Brasileira - FAB de 1976, na escala de 1:10.000, com posterior validação em campo da faixa preenchida. É importante salientar que na faixa preenchida manualmente, não foi possível ter a mesma riqueza de detalhes verificada na classificação automática realizada por Zaroni (2006), uma vez que se buscou contornar polígonos com maior representatividade espacial.

Para elaboração do mapa de uso e ocupação do solo em respeito ao artigo $2^{\circ}$ do Código Florestal Brasileiro - CFB, que prevê a manutenção da vegetação primitiva (floresta) ou natural em áreas onde a declividade é superior a $45^{\circ}$, e, ao entorno das nascentes, lagos entre outros, e, para margens de rios de até 10 metros, mantendo uma área de mata ciliar de 30 metros de cada lado, entre outros, foi elaborada uma área de contorno levando-se em consideração o Modelo Digital de Elevação - MDE, a drenagem, os lagos e as nascentes. O MDE contribuiu para definição da rede de drenagem, da faixa de 30 metros ao redor de rios, lagos, nascente e para áreas iguais ou superiores a $45^{\circ}$ de declividade, denominadas de Área de Proteção Ambiental - APP. Uma vez realizado tal procedimento, reclassificou-se o mapa de uso e ocupação atual, em outro, levando-se em consideração o CFB.

\section{RESULTADOS E DISCUSSÃO}

\subsection{Uso e ocupação do solo atual}

Na FIGURA 2 e TABELA 1, pode-se observar os valores absolutos e percentuais de cada tipo de uso e ocupação do solo atual na bacia do Córrego Santa Maria.

O predomínio da pastagem na bacia é reflexo dos diversos ciclos econômicos pelos quais passou a região noroeste fluminense onde está inserido a bacia experimental do Córrego Santa Maria, com destaque para o café, cana-de-açúcar, algodão e pecuária extensiva, que foram realizadas sem nenhuma prática de manejo e conservação de solo, ocasionando o escoamento superficial e a aceleração dos processos erosivos como pode ser visto na FIGURA 3.

A partir da década de 1960, a bacia do Córrego Santa Maria apresentou uma característica peculiar em relação ao uso e ocupação do solo do noroeste fluminense, pois teve início à olerícula do tomate em áreas que pertenciam ao pastoreio. Essa atividade agrícola realizada sem prática de manejo e conservação do solo, como verificada na bacia do Córrego Santa Maria, exige um elevado consumo de água promovendo sua escassez na bacia. Tal fato contribui para que alguns produtores construam pequenos reservatórios, afetando o comportamento hidrossedimentológico da bacia do Córrego Santa Maria, e, também canalizem água cada vez mais próxima das nascentes, podendo ocasionar disputas futuras por esse recurso.

Os fragmentos de Mata Atlântica que ainda existem na bacia estão em sua maioria em áreas de difícil acesso que não foram utilizadas ao longo dos diversos ciclos econômicos pelos quais passou a região, tendo importância fundamental para recarga do aquífero, na minimização das taxas de produção de sedimentos e movimentos de massa. 
Aplicação do Código Florestal Brasileiro como Subsídio para o Planejamento Ambiental: um Estudo de Caso na Região Noroeste do Estado do Rio de Janeiro

Eberval Marchioro, Nelson Ferreira Fernandes, José Ronaldo de Macedo,Silvio B. Bhering, Alexandre Ortega

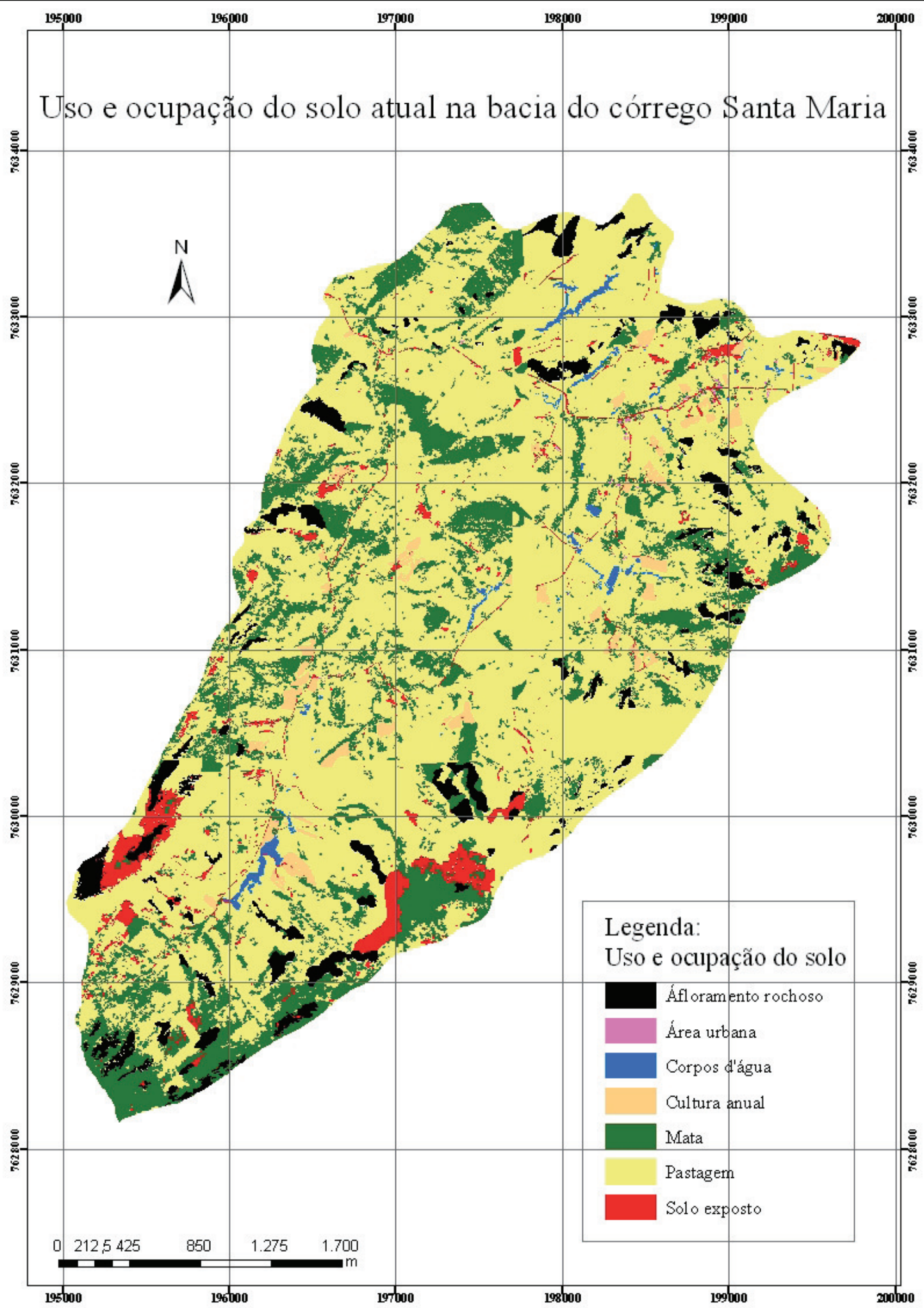

FIGURA 2: Mapa de uso e ocupação do solo atual da bacia do Córrego Santa Maria no noroeste do Estado do Rio de Janeiro.

Sociedade \& Natureza, Uberlândia, 22 (1): 11-21, abr. 2010 
Aplicação do Código Florestal Brasileiro como Subsídio para o Planejamento Ambiental: um Estudo de Caso na Região Noroeste do Estado do Rio de Janeiro Eberval Marchioro, Nelson Ferreira Fernandes, José Ronaldo de Macedo, Silvio B. Bhering, Alexandre Ortega

TABELA 1: Uso e ocupação do solo considerando o Código Florestal Brasileiro (CFB).

\begin{tabular}{c|c|c|c|c}
\hline & \multicolumn{2}{|c}{ Uso e ocupação Atual } & \multicolumn{2}{c}{ Código Florestal Brasileiro } \\
\hline Classe & Área (ha) & Porcentagem (\%) & Área (ha) & Porcentagem (\%) \\
\hline APP & $*$ & $*$ & 579,96 & 42,75 \\
\hline Área urbana & 1,16 & 0,09 & 1,06 & 0,08 \\
\hline Corpo de água & 10,32 & 0,76 & 10,32 & 0,76 \\
\hline Cultura anual & 26,76 & 1,97 & 23,00 & 1,70 \\
\hline Solo Exposto & 50,22 & 3,71 & 16,59 & 1,22 \\
\hline Afloramento Rochoso & 73,52 & 5,42 & 73,52 & 5,42 \\
\hline Mata & 267,72 & 19,74 & 121,54 & 8,96 \\
\hline Pastagem & 926,78 & 68,31 & 530,50 & 39,11 \\
\hline Total & $\mathbf{1 3 5 6 , 4 8}$ & $\mathbf{1 0 0 , 0 0}$ & $\mathbf{1 3 5 6 , 4 8}$ & $\mathbf{1 0 0 , 0 0}$ \\
\hline
\end{tabular}

* No uso e ocupação do solo atual, a classe área de preservação permanente é inexistente.

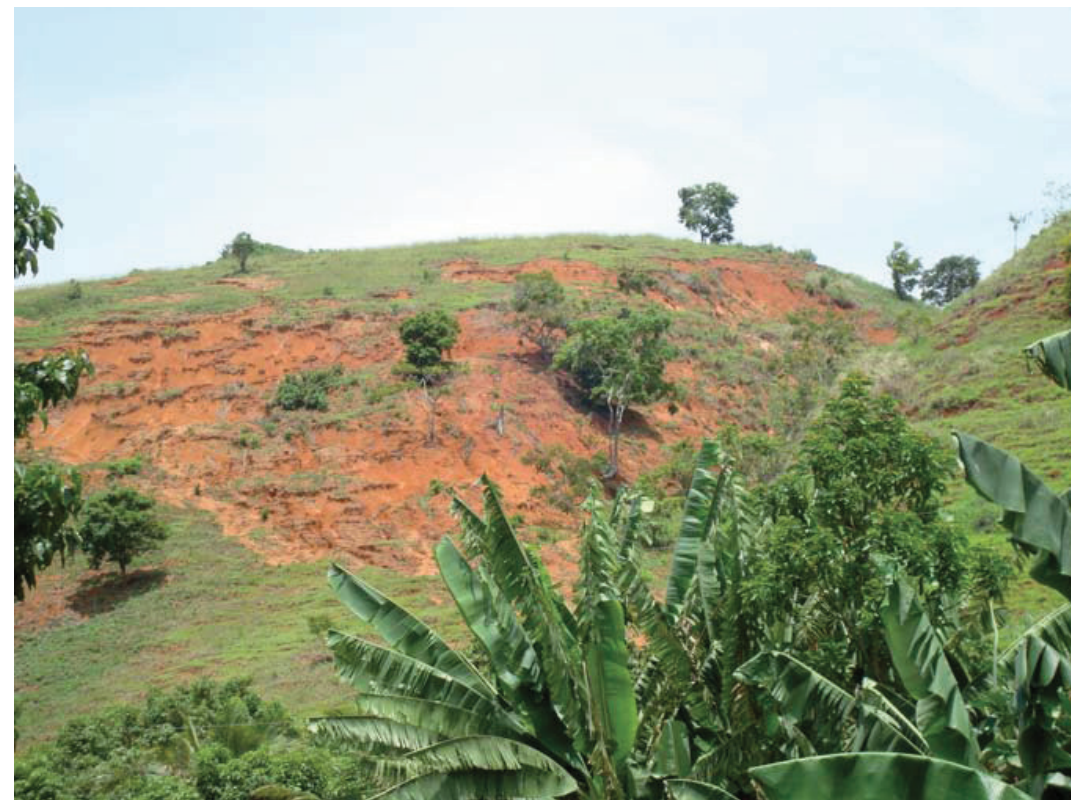

FIGURA 3: Erosão laminar do solo oriundos do processo de mau uso do solo na bacia do Córrego Santa Maria no noroeste do Estado do Rio de Janeiro (Foto: Marchioro, 2007).

\subsection{Aplicação do Código Florestal Brasileiro}

Conforme pode ser observado na TABELA 1 e na FIGURA 4, e, levando-se em consideração a aplicação do CFB, verifica-se que a principal área de conflito de uso e ocupação ocorreu no item pastagens, com uma diminuição de 389,79 ha ou $29,06 \%$ de seu uso original. 
Aplicação do Código Florestal Brasileiro como Subsídio para o Planejamento Ambiental: um Estudo de Caso na Região Noroeste do Estado do Rio de Janeiro

Eberval Marchioro, Nelson Ferreira Fernandes, José Ronaldo de Macedo,Silvio B. Bhering, Alexandre Ortega

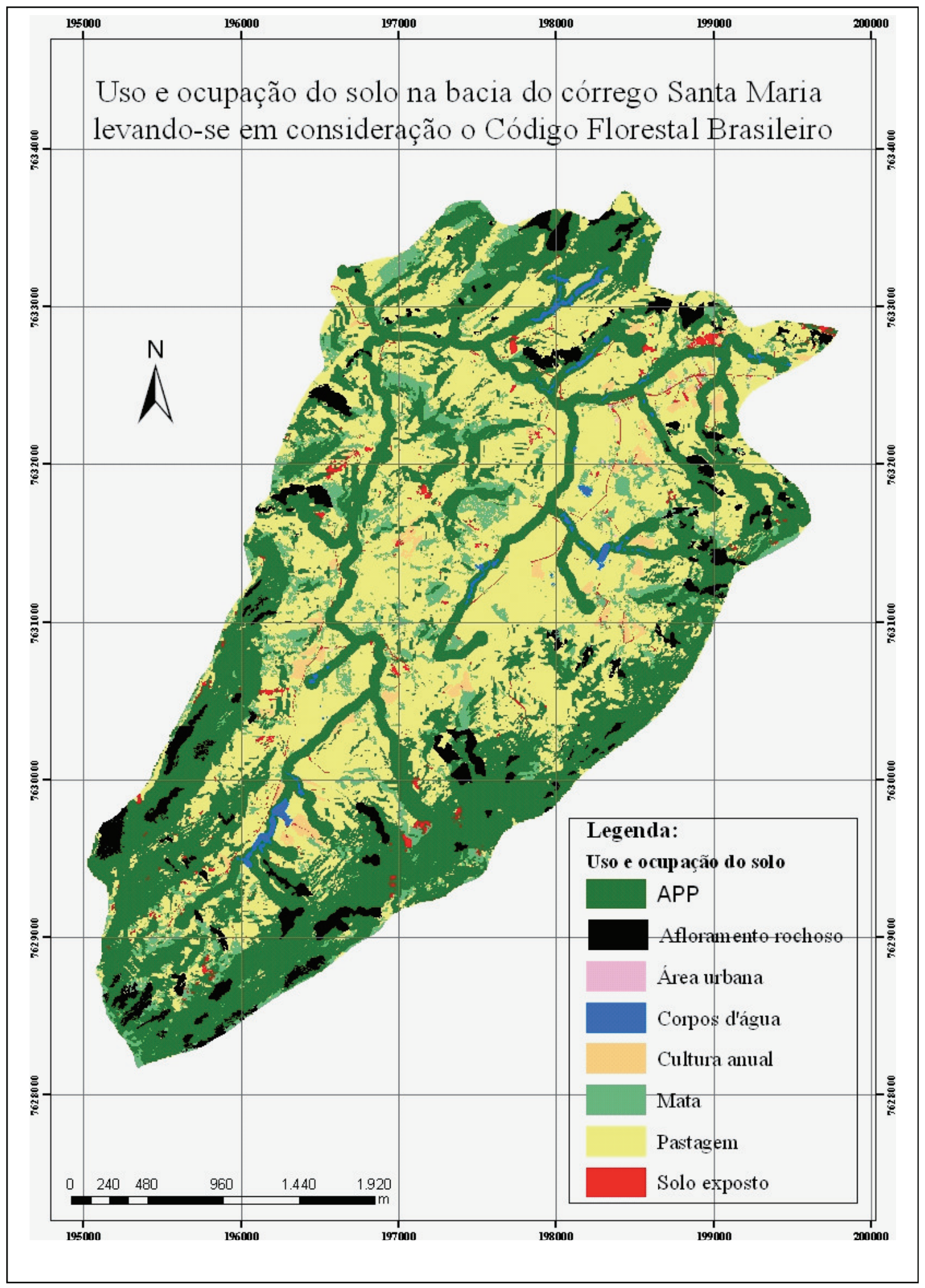

FIGURA 4: Mapa de uso e ocupação do solo da bacia do Córrego Santa Maria aplicando o Código Florestal Brasileiro.

Sociedade \& Natureza, Uberlândia, 22 (1): 11-21, abr. 2010 
Outra categoria que teve uma redução expressiva foi a de solo exposto que originalmente possuía 50,22 ha ou $3,72 \%$ do uso atual, passando para 16,59 ha ou $1,22 \%$ do uso e ocupação com o CFB. A classe área urbana sofreu uma alteração de 1,16 ha $(0,09 \%)$ para 1,06 ha $(0,08 \%)$, totalizando 10 ha. As classes corpo de água e afloramento rochoso não tiveram nenhuma alteração no que diz respeito a sua representatividade espacial da bacia.

Uma das principais preocupações no uso do CFB para bacias rurais refere-se à diminuição das áreas agrícolas. Contudo, observa-se que considerando somente a aplicação de parte do CFB na bacia do Córrego Santa Maria, as áreas atualmente utilizadas para a agricultura (olerícula de tomate, principalmente) apresentariam uma diminuição de apenas 3,76 ha. Como essa atividade agrícola na bacia é realizada de forma itinerante, restariam ainda para a rotação agrícola as áreas ocupadas pelas pastagens, que podem ser incorporadas ao sistema produtivo utilizando-se práticas adequadas de manejo e conservação dos solos.

Admitindo tal situação, poderiam ocorrer apenas conflitos entre as áreas ocupadas para pastagens em relação à voltada para agricultura, sendo solucionada com a difusão de práticas de manejo e conservação adequadas na bacia. Ainda em relação à pecuária, o conflito com a área de APP pode ser solucionado com práticas de manejo que contemplem ou garantam aumento da produtividade.

Em relação à diminuição da área de solo exposto com a aplicação do $\mathrm{CFB}$, isto promoveria aumento da infiltração de água no solo, contribuindo para a minimização da erosão do solo e aumento da recarga do aquífero. O aumento da infiltração também ocasionaria redução das taxas pico de vazão (minimizando enchentes) e maximização da vazão média durante o período de diminuição da precipitação que ocorre notadamente entre junho e agosto.

Do ponto de vista da categoria área urbana, a principal área conflitante refere-se às margens dos rios, lagoas e nascentes, que pode ser amenizada com a realocação das famílias para áreas próximas as atuais, mas que não estejam dentro das áreas de APP sem promover a desestruturação sócio-econômica e cultural.

Apesar da aplicação do CFB na bacia do Córrego Santa Maria não ocasionar conflito significante em relação às terras utilizadas atualmente para agropecuária, em outras bacias ocorre o contrário. Na bacia do rio Alegre no Espírito Santo, Nascimento et al. (2005), verificaram que de um total de 9.566,9 ha pertencentes a áreas de APP, $7.749,9$ ha possuem uso conflitando com a pastagem $(10,24 \%)$ e cafezais, com 64,49\%. Trentini (2004) abordou o conflito existente em relação à aplicação do CFB no meio rural do alto Uruguai no Oeste Catarinense, especificamente em seus artigos $2^{\circ}$ e $3^{\circ}$, e verificou que a maior parte da pecuária suína ocupa áreas de APP. Tourinho (2005) analisou o impacto do CFB na microbacia do rio Miringüava no Paraná que possui uma área de $161,75 \mathrm{~km}^{2}$ e encontrou situação de degradação das áreas de APP.

\section{CONCLUSÕES}

A aplicação do Código Florestal Brasileiro mostrou-se perfeitamente factível na bacia do Córrego Santa Maria, pois o uso conflitante em relação à agricultura e área urbana é baixo, e, do ponto de vista pecuário, esse conflito pode ser amenizado com práticas de manejo e conservação que propiciem menor uso da terra para o pastoreio extensivo.

Em relação à categoria solo exposto, a aplicação do CFB promoveria sua substituição para APP (representada por florestas), diminuindo a áreas potenciais de produção de sedimentos $\mathrm{e}$ desenvolvimento de feições erosivas na bacia.

As modificações no uso e ocupação promovidas pela utilização de florestas nas áreas recomendadas pelo artigo $2^{\circ}$ do $\mathrm{CFB}$, onde hoje está sob outros usos, produziriam alterações no comportamento hidrosedimentológico da bacia, 
Aplicação do Código Florestal Brasileiro como Subsídio para o Planejamento Ambiental:

um Estudo de Caso na Região Noroeste do Estado do Rio de Janeiro

Eberval Marchioro, Nelson Ferreira Fernandes, José Ronaldo de Macedo,Silvio B. Bhering, Alexandre Ortega

promovendo maior interceptação de águas pluviais e infiltração, diminuição do escoamento superficial, corroborando para a minimização da concentração de sólidos no canal e, consequente assoreamento, aumento da recarga subterrânea, culminando com a redução da escassez hídrica.

Para aplicação efetiva do CFB é importante ocorrerem ações que permitam a difusão de técnica de manejo e conservação do solo pelos órgãos governamentais responsáveis, visando contribuir para aumento da produção agropecuária, sem necessariamente, incorporarem novas áreas agrícolas, minimizando a pressão e os conflitos sobre a terra.

\section{AGRADECIMENTOS}

Ao Projeto "Planejamento conservacionista das terras e modelagem preditiva de sistema aquíferos do cristalino, para recarga hídrica em bacias hidrográficas de relevo acidentado", financiado pelo "Programa de Apoio ao Desenvolvimento de Tecnologias Agropecuárias para o Brasil PRODETAB" e a Coordenação de Aperfeiçoamento de Pessoal de Nível Superior (Capes) pela concessão da bolsa de doutorado.

\section{REFERÊNCIAS}

BHERING, S. B.; PEREIRO, N. R.; MACEDOS, J. R.; CHAGAS, C. S.; SILVA, E. F.; PRADO, R. B. e NETO, N. C. S. Caracterização edafoambiental das microbacias de Cambiocó e Santa Maria no Município de São José de Ubá, região noroeste do Estado do Rio de Janeiro para fins de planejamento conservacionista. In: IV WORKSHOP DO PROJETO GESTÃO PARTICIPATIVA DA SUBBACIA DO RIO SÃO DOMINGOS/RJ, Rio de Janeiro - Geparmbh, 2005. Anais... Rio de Janeiro, 2005.

CASSETI, V. Ambiente e apropriação do relevo. Editora Contexto. 1991. 147p.

CUNHA, S. B. GUERRA, A. J. T. Degradação ambiental. In: GUERRA, A. J. T. e CUNHA, S.
B. (Ed.). Geomorfologia e meio ambiente. Rio de Janeiro: Editora Edgard Blücher.1, 1996. p. 335 - 379.

DANTAS, M. E. Geomorfologia do Estado do Rio de Janeiro - Texto explicativo do mapa Geomorfológico do Estado do Rio de Janeiro na Escala 1:50.000. Companhia de Pesquisa de Recursos Minerais Departamento de Recursos Minerais - CPRM/DRM: 2000. $60 \mathrm{p}$.

FUNDAÇÃO CENTRO DE INFORMAÇÕES E DADOS DO RIO DE JANEIRO (CIDE). IQMverde: indice de qualidade dos municípios. 2. ed. ampl. rev. Rio de Janeiro, 2003. 1CD-ROM.

GONÇALVES,A. O.; FIDALGO, E. C.C.; BASTOS, C. L.; ABREU, M. B. Caracterização climática da bacia do rio São Domingos. In: WORKSHOP DE INTEGRAÇÃO DE INFORMAÇÕES OBTIDAS NO ÂMBITO DO PROJETO PRODETAB AQUÍfEROS - Embrapa solos. Rio de Janeiro. Anais... Rio de Janeiro: CD, 2006.

HEILBRON, M. D. B. P.; NOGUEIRA, J. R.; ALMEIDA, J. C. H.; TUPINAMBÁ, M.; GERALDES, M. C.; GUIA, C.; MIRANDA, A. W. A.; SILVA FILHO, R. S.; MEDEIROS, F. F. F. e MANSUR, K. Geologia da bacia do rio São Domingos, São José de Ubá, Rio de Janeiro. In: $9^{\circ}$ SIMPÓSIO DE GEOLOGIA DO SUDESTE - (SBG), Niterói - RJ, 2005. Anais... Niterói - RJ, 2005. 118 p.

MARCHIORO,E. Modelagem hidrosedimentológica na bacia do Córrego Santa Maria: Subsídios à Aplicação de Práticas de Conservação de Água e Solo no Noroeste Fluminense. 2008, 196f. Tese (Doutorado) - Programa Pós-graduação em Geografia da UFRJ. 2008.

MOURA, N. N. Percepção de risco do uso de agrotóxicos: o caso dos produtores de São José de Ubá/RJ. 2005, 92f. Dissertação (Mestrado em Desenvolvimento, Agricultura e Sociedade) Programa de Pós-graduação em Desenvolvimento, Agricultura e Sociedade., UFRRJ, Rio de Janeiro, 2005.

Sociedade \& Natureza, Uberlândia, 22 (1): 11-21, abr. 2010 
NASCIMENTO, M. C.; SOARES, V. P.; RIBEIRO, C. A. Á. S. e SILVA, E. Uso do geoprocessamento na identificação de conflito de uso da terra em áreas de preservação permanente na bacia hidrográfica do rio Alegre, Espírito Santo. Ciência Florestal, v.15, 2005. p. 207 - 220.

PRADO, R.; MACEDO, J. R.; PEREZ, D.; GONÇALVES, A. O.; MARINHO, A. G.; CARVAlHO, B. A.;RANGEL, M. C. Monitoramento de indicadores de qualidade da água como subsídio à gestão de recursos hídricos em microbacia do município de São José de Ubá RJ. In: IV WORKSHOP DO PROJETO GESTÃO PARTICIPATIVA DA SUB-BACIA DO RIO SÃO DOMINGOS/RJ - Rio de Janeiro - Geparmbh. Anais... Rio de Janeiro, 2005.

REIS, A. P. e MANSUR, K. L. Sinopse Geológica do Estado do Rio de Janeiro na escala 1:400.000. Niterói/RJ, 1995.

TRENTINI, E. C. Agricultura criminosa: atividades agrícolas avaliadas á luz do Código Florestal Brasileiro de 1965. 2004, 123f . Dissertação (Mestrado em Agroecossistemas) Programa de Pós-graduação em Agroecossistemas, UFSC, Florianópolis, 2004.

TOURINHO, L. A. M. O Código Florestal na pequena propriedade rural: um estudo de caso em três propriedades na microbacia do rio Miringüava. 2005, 95f. Dissertação (Mestrado em Geografia) Programa de Pós-graduação em Geografia UFPR, Paraná, 2005.

ZARONI, M. J. Estimativa da produção de sedimentos em bacias hidrográficas por meio do modelo de erosão USLE e do índice de transferência de sedimentos - SDR. 2006, 143f. Dissertação (Mestrado em Geografia) - Departamento de Geografia/Programa de Pós-graduação em Geografia, Universidade Federal do Rio de Janeiro, Rio de Janeiro, 2006. 